Revista de Derecho Político, núm. 24, 1987, pp. 173-193

\title{
MEMORIA DE LA II LEGISLATURA EN EL CONGRESO DE LOS DIPUTADOS
}

La presente Crónica parlamentaria comprende la II Legislatura constitucional, 1982-1986, exceptuando su primer período de sesiones que fue recogido en esta misma Sección en un número anterior de la $R e-$ vista ${ }^{1}$.

El Presidente del Gobierno, Felipe González, haciendo uso de la facultad que le confiere en exclusiva el artículo 115 de nuestra Constitución, propuso al Rey la disolución de las Cortes Generales que fue decretada por el Jefe del Estado el 23 de abril de 1986. Se ponía fin de esta forma a una Legislatura importante que, al igual que la anterior, 1979-1982, tuvo una duración de tres años y medio. La decisión de poner término anticipadamente al mandado parlamentario venía justificada, no por el desencadenamiento de una grave crisis política, sino por la idea de poder elegir el momento más idóneo para llevar a cabo la apellatio ad populum.

A lo largo de esta Legislatura se produjo un importante desarrollo de la Constitución, tanto en lo que respecta a los derechos y libertades fundamentales, como por lo que se refiere a las instituciones.

Ha sido también una Legislatura marcada por el absoluto dominio del Grupo Socialista, que no sólo monopolizó el Gobierno, sino que dejó sentir su impronta hegemónica en los trabajos parlamentarios.

En cuanto al cumplimiento del programa de gobierno presentado ante el Congreso por el entonces candidato a la Presidencia del Gobierno, Felipe González, en la sesión plenaria del día 30 de noviembre de 1982, hemos de señalar los siguientes puntos:

1 Véase Manuel Gonzalo, “Crónica parlamentaria " en Revista de Derecho Político, núm. 18/19, 1983, pp. 212-224. 
1. Los propósitos del entonces candidato en el terreno de las Autonomias se vieron materializados en la aprobación de los Estatutos de Extremadura, Baleares, Madrid y Castilla-León, asi como en la aprobación de la Ley del Fondo de Compensación Interterritorial y en la del Proceso Autonómico.

2. En cuanto a la proyección extranjera de España que fue uno de los pilares sobre los que se asentó el programa del candidato, el 12 de junio de 1985 se firmó solemnemente en Madrid el Tratado de Adhesión de España a las Comunidades Europeas (CECA, CEE, EURATOM).

3. Por lo que se refiere al desarrollo legislativo de los derechos y libertades reconocidos y garantizados en nuestra Ley Fundamental, se aprobaron los proyectos de ley del derecho de reunión, del derecho de rectificación, del procedimiento de Habeas Corpus, de Asistencia Letrada al detenido y al preso, del derecho a la objeción de conciencia, de los derechos y libertades de los extranjeros en España, del derecho a la educación, de Libertad Sindical, del derecho de asilo, y del derecho a participar en el proceso Legislativo (Iniciativa Legislativa Popular). Aunque figuraba en el programa gubernamental, el Gobierno no envió el anunciado proyecto de ley sobre el derecho de huelga.

4. En lo que respecta a los órganos constitucionales, se aprobó la Ley Orgánica del Poder Judicial.

5. En materia de política laboral, de bienestar y económica, se tramitaron y aprobaron importantes medidas:

a) En el campo laboral hay que destacar las siguientes leyes: de fijación de la jornada máxima legal en $\mathbf{4 0}$ horas y de las vacaciones anuales mínimas en treinta días; de protección por desempleo; sobre modificación de determinados artículos del Estatuto de los Trabajadores;

b) En el ámbito de la política de bienestar podemos señalar por su importancia las siguientes normas legislativas: Ley de medidas urgentes para la racionalización de la estructura y de la acción protectora de la Seguridad Social (Ley de Pensiones); Ley General de Sanidad.

c) $\mathrm{Y}$ en el terreno económico, hay que destacar: la ley sobre reconversión y reindustrialización, la ley de reconversión del sector petrolero y la de explotación unificada del sistema eléctrico nacional.

No se tramitaron, a pesar de haber sido anunciadas en la sesión de investidura, la ley General de la Seguridad Social, el Estatuto del Minero, la Ley de Huelga y la ley de regulación del trabajo doméstico. 
6. La anunciada reforma de la Administración Pública se llevó a cabo mediante la aprobación de las siguientes leyes: de medidas urgentes para la reforma de la Administración Pública; de incompatibilidades del personal al servicio de las Administraciones Públicas.

7. En materia de política educativa cabe señalar la aprobación de la Ley Orgánica del Derecho a la Educación y la Ley de Reforma Universitaria.

8. Por último, el compromiso del candidato gubernamental para convocar un referéndum sobre la permanencia de España en la Alianza Atlántica se vio cumplido el 15 de marzo de 1985.

\section{PRACTICAS APLICATIVAS DE LA CONSTITUCION}

Durante la II Legislatura constitucional se produjeron dos prácticas aplicativas de la Constitución que ofrecen novedad, ya que no encontramos precedentes en la anterior Legislatura: se trata del Informe a las Cortes Generales del Defensor del Pueblo y de la autorización por el Congreso de los Diputados de la propuesta del Presidente del Gobierno de celebrar un referéndum consultivo según lo dispuesto en el artículo 92 de nuestra Norma Fundamental.

\section{Prácticas de carácter no legislativo}

\section{a) Disolución del Congreso}

Es la segunda vez desde que se aprobó la Constitución que el Congreso de los Diputados finalizaba su mandato por disolución decretada a propuesta del Presidente del Gobierno según lo dispuesto en el artículo 115 de la Constitución.

\section{b) Referéndum cnsultivo}

Una importante novedad de esta Legislatura fue la de que por primera vez desde la aprobación de la Constitución de 1978, el Congreso de los Diputados autorizó por mayoría absoluta, conforme a lo dispuesto en el artículo 92.2 CE y en el artículo 6 de la LO 3/1980 de 18 de enero sobre las distintas modalidades de referéndum, la propuesta del Presidente del 
Gobierno de celebrar un referéndum sobre la permanencia de España en la Alianza Atlántica (DSC n. $\left.{ }^{\circ} 267\right)^{2}$.

\section{c) Informe del Defensor del Pueblo}

En cumplimiento del mandato recogido en el artículo 54 in fine de la Constitución, el Defensor del Pueblo, elegido por las Cortes Generales en el primer periodo de sesiones de esta Legislatura ${ }^{3}$, envió al Congreso de los Diputados y al Senado dos informes correspondientes a su gestión realizada durante el año 1983 (BOCG, $\mathrm{E}, 47)$ y 1984 (BOCG, $\mathrm{E}, 122)$.

\section{d) Informes del Tribunal de Cuentas}

Cumpliendo el mandato constitucional del artículo $136.2 \mathrm{CE}$, el Tribunal de Cuentas envio a las Cortes Generales tres informes correspondientes a la Cuenta General del Estado de 1978 (BOCG, E, TC, 1), 1979 (BOCG, E, TC, 2) y 1980 (BOCG, E, TC, 11).

\section{e) Memoria del Consejo General del Poder Judicial}

Es también una novedad en relación a la anterior Legislatura el envio al Congreso de los Diputados por parte del Consejo General del Poder Judicial, de una Memoria-Dictamen sobre su actividad en 1983 (BOCG, E, 36 y 57).

\section{Prácticas de carácter normativo}

En las prácticas de carácter normativo recogemos aquellas que se refieren al desarrollo legal de la Constitución en numerosos puntos, tanto en lo que afecta al campo de los derechos y libertades, como al terreno de las instituciones. Asimismo, introducimos en este apartado los Decretos-leyes dictados por el Gobierno al amparo del artículo $86 \mathrm{CE}$, y convalidados por el Congreso de los Diputados.

\subsection{Leyes Orgánicas}

a) Reforma del artículo 417 bis del Código Penal: despenalización de tres supuestos de aborto: L.O. 9/1985 de 7 de julio

2 Vease nuestra Nota en Revista de Derecho Politico, núm. 23.

3 Véase Revista de Dereco Político, núm. 18/19, 1983, pp. 220. 
En 1983, el Gobierno envió al Congreso un proyecto de ley orgánica de despenalización de tres supuestos de aborto (BOCG, $A, 10)$ que encontró una enconada oposición en el Grupo mayoritario de la Cámara Baja, el Grupo Popular, que presentó alternativamente una Proposición de ley sobre protección de los hijos no deseados (BOCG, $B, 25)$, que fue rechazada (DSC n. ${ }^{\circ} 69$ ). Contra esta ley de reforma del artículo 417 bis del Código penal, aprobada por el Congreso en votación final sobre el conjunto del proyecto (DSC N. ${ }^{\circ} 40,61,62$ y 63), el Grupo Popular presentó ante el Tribunal Constitucional recurso previo de inconstitucionalidad. En 1985 este alto Tribunal dictó sentencia (STC 53/1985) apreciando inconstitucionalidad en la regulación de las garantías de comprobación de los supuestos despenalizados, pero no en éstos. El Gobierno envió consiguientemente un nuevo proyecto de ley (BOCG, $A, 10$ bis) introduciendo las garantías exigidas y el texto fue aprobado.

\section{b) Modificación de la Ley de Enjuiciamiento Criminal: L.O. 7/1983 de 23 de abril}

El Congreso de los Diputados aprobó en 1983 el proyecto de ley orgánica por el que se modificaban los artículos 503 y 504 de la LECRIM (BOCG, 7 y 100) (DSC n. 146 y 174).

Asimismo, sobre la reforma de la Ley de Enjuiciamiento Criminal se presentaron dos Proposiciones de Ley por el Grupo Popular: sobre la modificación del artículo 436 sobre actos de identificación de los testigos, (BOCG, B, 51), que fue desestimada (DSC n. ${ }^{\circ} 146$ ), y sobre modificación del artículo 849. 2 (BOCG, B, 56) que fue aprobada (DSC n. ${ }^{\circ} 160$ ).

\section{c) Derecho de Reunión: L.O. 9/1983 de 15 de julio}

Reconocido en el artículo 21 de nuestra Constitución, el proyecto de ley orgánica reguladora del derecho de reunión enviado por el Gobierno venía a suplir una importante laguna en el Ordenamiento español (BOCG, A, 6; DSC n. ${ }^{\circ 24)}$.

\section{d) Reforma Universitaria: L.O. 11/1983 de 25 de agosto}

Si durante la I Legislatura Constitucional la autonomía universitaria trajo de cabeza a varios Gobiernos de UCD, el Gobierno socialista sacó adelante en 1983, enfrentándose a diversos medios y sectores universitarios, el proyecto de ley orgánica de Reforma Universitaria (BOCG, A, 28; DSC n. ${ }^{\circ} 47,53$ y 54$)$.

\section{e) Derecho a la Educación: L.O. 8/1985 de 3 de julio}

En medio de numerosas protestas procedentes de sectores educativos, religiosos y de asociaciones de padres de familia, se aprobó en 
1983 la ley orgánica reguladora del derecho a la educación (BOCG, A, 49; DSC n. ${ }^{\circ} 64,83,84,86$ y 87). Esta ley que desarrolla el artículo 27 de la Constitución fue recurrida en inconstitucionalidad por el Grupo Popular. El Tribunal Constitucional dictó sentencia en 1985 no apreciando inconstitucionalidad, salvo en el artículo 22 y la Disposición transitoria cuarta. (STC 77/85).

\section{f) Derecho de Rectificación: L.O. 2/1984 de 26 de marzo}

Aunque el derecho de rectificación no está reconocido en la Constitución, el Congreso de los Diputados aprobó un proyecto de ley orgánica que consagra el derecho de toda persona, física o jurídica, a rectificar la información difundida por cualquier medio de comunicación acerca de hechos que la aludan y considere inexactos o nocivos en su divulgación (BOCG, A, 35; DSC n. ${ }^{\circ} 69$ ).

g) Derecho al secreto de las comunicaciones: L.O. 7/1984 de 15 octubre

Con el fin de proteger y garantizar el derecho al secreto de las comunicaciones reconocido en el artículo 18.3 CE, el Grupo Mixto presentó una proposición de ley sobre tipificación penal de la colocación indiscriminada y arbitraria de escuchas telefónicas (BOCG, B, 48) que fue aprobada (DSC n. ${ }^{\circ} 87$ ).

\section{h) Iniciativa legislativa popular: L.O. 3/1984, de 26 de marzo}

De acuerdo con el mandato del artículo $87.3 \mathrm{CE}$, el proyecto de ley orgánica sobre iniciativa legislativa popular (BOCG, $A, 48)$ regula las formas de ejercicio y requisitos de la participación de los ciudadanos en el proceso legislativo (DCS $n .^{\circ} 79$ y 80 ).

\section{i) Procedimiento de "Habeas Corpus": L.O. 6/1984, de 24 de mayo}

En desarrollo del artículo 17.4 CE, el Gobierno envió a las Cortes un proyecto de ley orgánica para regular el procedimiento de Habeas Corpus (BOCG, A, 56) en el que quedó subsumida una proposición de ley del Grupo Vasco sobre el mismo tema (BOCG, B, 22). El proyecto fue aprobado sin grandes discusiones (DSC $n .{ }^{\circ} 68$ ).

\section{j) Asistencia letrada al detenido y al preso: L.O. 14/1983, de 12 de diciembre}

El Grupo Mixto presentó una Proposición de ley sơbre esta importante materia que desarrolla el artículo 24 de la Constitución, pero fue reti- 
rada ante el envío del Gobierno a la Cámara de un proyecto de ley orgánica de asistencia letrada al detenido y al preso y modificativa de los artículos 520 y 527 de la Ley de Enjuiciamiento Criminal (BOCG, B, 20; DSC n. ${ }^{\circ} 50$ y BOCG, A, 22; DSC n. ${ }^{\text {os }} 60,79$ y 80).

\section{k) Objeción de conciencia: L. 48/1984, de 29 de diciembre}

El Congreso de los Diputados recibió del Gobierno en 1984 un proyecto de ley orgánica por el que regulaba la objeción de conciencia y la prestación social sustitutoria contemplados en el artículo 30.2 CE (BOCG, A, 79; DSC n. ${ }^{\circ} 93,117,118$ y 119). La Cámara prestó su conformidad al Acuerdo de la Comisión Constitucional para que el proyecto que regulaba la objeción de conciencia fuera dividido en dos: una ley ordinaria reguladora de la objeción de conciencia y de la prestación social sustitutoria, y una Ley orgánica que regule el régimen de recursos en casos de objeción de conciencia y su reglamento penal (DSC n. ${ }^{\circ} 124$ ).

Finalmente, se aprobó el proyecto de ley reguladora de la objeción de conciencia y de la prestación social sustitutoria con las enmiendas del Senado (DSC n. ${ }^{\circ} 150$ ). Esta ley fue recurrida en inconstitucionalidad por el Defensor del Pueblo, sin que se haya dictado hasta ahora sentencia al respecto.

\section{1) Libertad sindical: L.O. 11/1985, de 2 de agosto}

La libertad sindical reconocida en el artículo 28 de nuestra Constitución fue objeto en 1984 de un proyecto de ley orgánica (BOCG, A, 82) que venía a colmar una importante laguna legal (DSC $n$. ${ }^{\text {s }} 97,119,120$, $121,122,133$ y 143). Contra ella se interpuso recurso de inconstitucionalidad, sobre el cual decidió el Alto Tribunal en una sentencia, de 29 de julio de 1985 (STC 98/1985, de 29 de julio).

\section{m) Poder Judicial: L.O. 6/1985, de 1 de julio}

El proyecto de ley orgánica del Poder Judicial enviado por el Gobierno en 1984 al Congreso (BOCG, A, 118) fue aprobado en 1985 en medio de grandes controversias referidas fundamentalmente a la composición y modo de elección del órgano de gobierno de los jueces: el Consejo General del Poder Judicial (DSCD n. ${ }^{\text {os }} 164,191,192,194,195,196$ y 220).

\section{n) Régimen electoral general: L.O. 5/1985, de 19 de junio}

En consonancia con lo dispuesto en el artículo 81.1 CE, una ley orgánica (BOCG, $A, 120$ ) regula el régimen electoral general, no presen- 
tando diferencias sustanciales, en cuanto al sistema electoral se refiere, con el R.D.L. de 18 de marzo de 1977 (DSC n. ${ }^{\text {os }} 174,191$ y 215).

\section{o) Derechos y libertades de los extranjeros en España: L.O. 7/1985, de 1 de julio}

A tenor de lo dispuesto en el artículo 13.1 de nuestra Norma Básica, los extranjeros gozarán en España de las libertades públicas que garantiza el Título I de la Constitución en los términos que establezcan los Tratados y la Ley. En desarrollo de este mandato constitucional, el Gobierno envió al Congreso de los Diputados un proyecto de ley orgánica sobre los derechos y libertades de los extranjeros en España (BOCG, A, 132), provocando con su aprobación (DSC n. ${ }^{\circ} 181,200,201$ y 215) airadas protestas de determinada comunidades, especialmente de las comunidades musulmanas de Ceuta y Melilla.

\section{p) Medidas antiterroristas: L.O. 9/1984, de 26 de diciembre}

Con base jurídica en el artículo $55.2 \mathrm{CE}$, el Gobierno envío al Congreso un proyecto de ley orgánica contra la actuación de bandas armadas y elementos terroristas que sustituyó a la aún más polémica Ley Antiterrorista de 1982 (BOCG, A, 81) (DSC n. ${ }^{\text {os }} 147,149$ y 174).

\section{q) Cuerpos y Fuerzas de Seguridad: L.O. 2/1986, de 13 de marzo}

Esta ley orgánica regula las funciones y el estatuto de los distintos Cuerpos y Fuerzas de seguridad: del Estado, Autónomas, locales, y Policía Judicial (BOCG, A, 163; DSC n. $\left.{ }^{\circ} 258,261,271\right)$.

\section{r) Código Penal Militar: L.O. 13/85, de 9 de diciembre}

El Congreso de los Diputados aprobó en 1985 el proyecto de ley orgánica del Código Penal Militar (BOCG, A, 123; DSC n. 220,246$)$, así como el de modificación del Código Penal en correlación con el Código Penal Militar (BOCG, A, 124; DSC n. ${ }^{\circ} 200$ ).

Asimismo, en esta materia, se aprobó el proyecto de ley orgánica del régimen disciplinario de las Fuerzas Armadas (BOCG, A, 131; DSC n. ${ }^{\circ}$ 189), y se presentó, pero caducó por disolución de la Cámara el de competencia y organización de la Jurisdicción Militar (BOCG, A, 195).

\section{s) Tratado de Adhesión de España a las Comunidades Europeas: L.O. 1/1986, de 1 de enero}

En virtud de lo dispuesto en el artículo 93 de la Constitución, las Cortes Generales autorizaron mediante ley orgánica la celebración del 
tratado de adhesión de España a las Comunidades Europeas, por el que se atribuyen a éstas el ejercicio de competencias derivadas del texto constitucional (BOCG, A, 156; DSC n. ${ }^{\text {os }} 221$ y 222).

t) Supresión del recurso previo de inconstitucionalidad: L.O. 4/1985, de 7 de junio

Esta ley, contra la que se presentó también recurso previo de inconstitucionalidad, suprimió el Capítulo II, del Título IV de la Ley Orgánica del Tribunal Constitucional. En su sentencia 53/85, este alto Tribunal desestimó el citado recurso.

\section{u) Estatutos de Autonomía}

En consonancia con lo dispuesto en el artículo $81.1 \mathrm{CE}$, los Estatutos de Autonomía son aprobados mediante ley orgánica. En esta segunda legislatura constitucional se aprobaron los siguientes:

- De Baleares (DSC n. ${ }^{\circ} 7,9$ y 13).

- De Castilla-León (DSC n. ${ }^{\circ s} 9$ y 13).

- De Extremadura (DSC n. ${ }^{\circ} 8$ ).

- De Madrid (DSC n. ${ }^{\circ}$ ).

\subsection{Decretos-leyes}

En el período 1982-1986 se tramitaron 38 Reales Decretos-leyes ante el Congreso de los Diputados. Todos ellos fueron convalidados y respecto a algunos se acordó su tramitación como proyectos de ley.

Señalamos a continuación los más importantes sometidos a la convalidación del Congreso:

- R.D.L. 23/1982, de 19 de diciembre, por el que se prorroga la aplicación del Fondo especial de protección al desempleo (DSC n. $\left.{ }^{\circ} 10\right)$.

- R.D.L. 2/1983, de 23 de febrero, de expropiación de bancos y otras sociedades que componen el Grupo Rumasa (DSC números 15 y 16). Se acordó su tramitación como proyecto de ley. 
- R.D.L. 8/1983, de 30 de noviembre, sobre reconversión y reindustrialización (DSC n. ${ }^{\circ}$ 89). Se acordó su tramitación como proyecto de ley.

- R.D.L. 2/1984, de 28 de marzo, sobre declaración del impuesto sobre la renta de las personas físicas (DSCD n. ${ }^{\circ} 117$ ).

\section{ACTIVIDAD LEGISLATIVA}

En este apartado trataremos de recoger los más relevantes proyectos y proposiciones de ley que por su indole o trascendencia deban quedar reflejados (todos los señalados fueron aprobados).

\section{Proyectos de ley}

BOCG, A

Materia

DSC n. ${ }^{\circ}$

4 Reforma del C.C. en materia de tutela.

39 y61

tela.

27 Organización de la Administración central del Estado.

47 y 52

26

Creación del organismo autónomo "Instituto de los derechos de la 49, DS comisión mujer».

n. ${ }^{\circ} 58$

Reforma urgente de la Ley de Enjuiciamiento Civil.

32 Regulación del derecho de asilo.

61 y 79

$46 \quad$ Medidas urgentes de saneamiento y regulación de las Haciendas Lo58,70 y 71 cales.

$52 \quad$ Modificación del art. 338 de la LECRIM. 
53 Ordenación del seguro privado.

68

$76 \quad$ Fondo de compensación interterri-

93,102 torial.

77 Medidas para la reforma de la función pública.

$91,127,128,143$

78

Incompatibilidades del personal al

$92,152,153$ y 17 servicio de las Administraciones Públicas.

Defensa de consumidores y usuarios.

$93,113,114,115$, 117 y 140

$89 \quad$ Protección civil.

106 y 175

96 Patrimonio Histórico Español.

$123,183,186$ y 211

97 Regulación de las bases de Régimen Local.

$133,136,165,166$, 167 y 187

109

Represión del fraude fiscal.

150

113

Cambiaria y del Cheque.

233

135

Aguas.

$187,207,208,210 y$ 224

145 General de Sanidad.

$215,216,245$

y 248

Impuesto sobre el valor añadido.

210,220 y 224

150 Medidas urgentes para la racionali-

224 zación de la estructura y de la acción protectora de la Seguridad Social. 
BOCG, A

Materia

DSC n.

151 Creación del Consejo General de 223 Formación Profesional.

154

Patentes

271

Asimismo hemos considerado de interés reseñar algunos proyectos de ley que caducaron en la anterior legislatura por disolución del Congreso de los Diputados el 23 de abril de 1986:

- PL General de Cooperativas (BOCG, A, 164).

- Bases de Régimen Jurídico de las Cámaras Agrarias (BOCG, A, 176).

- PL de Propiedad Intelectual (BOCG, A, 184).

- PL por el que se aprueba el Estatuto de Ceuta (BOCG, A, 191).

- PL por el que se aprueba el Estatuto de Melilla (BOCG, $A, 192)$.

- PL de ordenación de los transportes terrestres (BOCG, A, 186).

- PL de Conflictos Jurisdiccionales (BOCG, A, 188).

- PL de reforma del Código Civil en materia de adopción (BOCG, A, 194).

\section{Proposiciones de Ley}

Se tramitaron 104 Proposiciones de ley, si bien sólo 25 llegaron a convertirse en ley. El Grupo Popular fue el que mayor número de Proposiciones de ley presentó (32), seguido del Grupo M. Catalana (23), Grupo Mixto (20) G. Socialista (5) y G. Vasco (5). El Senado sólo remitió una (1) proposición de ley y los Parlamentos autónomos (14): Baleares (4), Canarias (3), Cataluña (3), Galicia (2), Andalucía (1) y Aragón (1).

A continuación señalamos algunas de las más importantes de las que fueron aprobadas: 


\begin{tabular}{|c|c|c|}
\hline BOCG, B & Materia & DSC n. \\
\hline 2 & $\begin{array}{l}\text { Desarrollo del art. } 154 \text { CE } \\
\text { (MINORIA CATALANA) }\end{array}$ & 13,48 y 68 \\
\hline 70 y 80 & $\begin{array}{l}\text { Regulación de las relaciones entre } \\
\text { el Defensor del Pueblo y figuras si- } \\
\text { milares de las Comunidades Autó- } \\
\text { nomas } \\
\text { (CORTES DE ARAGON Y PARLA- } \\
\text { MENTO DE ANDALUCIA) }\end{array}$ & 189,223 y 240 \\
\hline 29 & $\begin{array}{l}\text { Autorización para otorgar a Cata- } \\
\text { luña un tercer canal de TV pública } \\
\text { (PARLAMENTO CATALAN) }\end{array}$ & 50 y 78 \\
\hline 56 & $\begin{array}{l}\text { Modificación del art. } 849.2 \text { LE- } \\
\text { CRIM } \\
\text { (G. POPULAR) }\end{array}$ & 137 \\
\hline 87 & $\begin{array}{l}\text { Modificación de la L.O. } 1 / 82 \text { de } 5 \\
\text { de mayo sobre protección del de- } \\
\text { recho al honor } \\
\text { (TODOS LOS GRUPOS) }\end{array}$ & 160 \\
\hline
\end{tabular}

\section{Iniciativa Legislativa Popular}

La Mesa del Congreso de los Diputados sólo recibió tres iniciativas legislativas populares, aunque no admitió a trámite ninguna de ellas. Fueron las siguientes:

- Mantenimiento de Altos Hornos del Mediterráneo (Mesa, 16 noviembre de 1983).

- Pensiones de Jubilación para administradores familiares amos/as de casa (Mesa, 27 de julio de 1984).

- Ibidem (Mesa, 26 de mayo de 1985). 


\section{Tratados y Convenios Internacionales}

En la pasada Legislatura fueron tramitados en el Congreso de los Diputados 137 Convenios Internacionales para su autorización (Art. 94.1 CE) y 138 para informar de su conclusión (Art. 94.2 CE).

\section{ACTIVIDAD FINANCIERA}

\section{Materia presupuestaria}

\begin{tabular}{|c|c|c|}
\hline BOCG, A & Materia & DCsn. ${ }^{\circ}$ \\
\hline 57 & $\begin{array}{l}\text { Presupuestos Generales del Es- } \\
\text { tado para } 1984 \text {. }\end{array}$ & $\begin{array}{l}87,71,72,73,74, \\
75,76,77,78 \text { y } 89 .\end{array}$ \\
\hline 119 & $\begin{array}{l}\text { Presupuestos Generales del Es- } \\
\text { tado para } 1985 .\end{array}$ & $\begin{array}{l}161,162,163,168 \\
169,170,171,172, \\
173,174 \text { y } 178 .\end{array}$ \\
\hline 171 & $\begin{array}{l}\text { Presupuestos Generales del Es- } \\
\text { tado para } 1986 \text {. }\end{array}$ & $\begin{array}{l}243,244,251,252 \\
253,254,255,256 \text { y } \\
264 .\end{array}$ \\
\hline
\end{tabular}

\section{Materia tributaria}

\begin{tabular}{|c|c|c|}
\hline$B O C G, A$ & Materia & DSC n. \\
\hline 161 & Impuestos especiales. & 263. \\
\hline 147 & Impuesto sobre el valor añadido. & 210,220 y 224 \\
\hline 172 & Reforma parcial del IRPF. & 263. \\
\hline $\begin{array}{c}36 \text { a } 44 \\
62,63 \\
64,69 y \\
72\end{array}$ & $\begin{array}{l}\text { Cesión de tributos del Estado a las } \\
\text { CCAA. }\end{array}$ & 78 y 93. \\
\hline 109 & $\begin{array}{l}\text { Modificación parcial de la Ley Ge- } \\
\text { neral Tributaria. }\end{array}$ & 200 y 201. \\
\hline
\end{tabular}


3. Ordenación general o singular de la Economía

\begin{tabular}{|c|c|c|}
\hline BOCG, A & Materia & DSC n. ${ }^{\circ}$ \\
\hline 18 & $\begin{array}{l}\text { Medidas financieras de estímulo a } \\
\text { la exportación. }\end{array}$ & 48. \\
\hline 29 & $\begin{array}{l}\text { Modificación de la Ley } 40 / 1979 \text { de } \\
10 \text { de diciembre sobre régimen ju- } \\
\text { rídico de control de cambios. }\end{array}$ & $8,51,52$ y 54 \\
\hline 65 & $\begin{array}{l}\text { Coeficientes de caja de los inter- } \\
\text { mediarios financieros. }\end{array}$ & 68,70 \\
\hline 84 & $\begin{array}{l}\text { Modificación de determinados arts. } \\
\text { del Estatuto de los Trabajadores. }\end{array}$ & $\begin{array}{l}99,129,131,132, \\
133 \text { y } 173 .\end{array}$ \\
\hline 103 & $\begin{array}{l}\text { Explotación unificada del sistema } \\
\text { eléctrico nacional. }\end{array}$ & 144. \\
\hline 117 & Reordenación del sector petrolero. & 152. \\
\hline $62(B)$ & $\begin{array}{l}\text { Modificación del tipo de interés le- } \\
\text { gal del dinero. }\end{array}$ & 129. \\
\hline
\end{tabular}

\section{ACTIVIDAD DE CONTROL}

1. Actos de control con eficacia jurídica

a) Investidura

La investidura del Presidente del Gobierno conforme a lo dispuesto en el artículo $99 \mathrm{CE}$ ya fue tratada en la Crónica Parlamentaria del número 18/19 de esta Revista.

b) Cuestión de confianza

En la pasada Legislatura constitucional, el Gobierno no presentó ante el Congreso ninguna cuestión de confianza. 
c) Moción de censura

Aunque el Grupo mayoritario de la Oposición, Grupo Popular, amenazó en varias ocasiones con la presentación de una moción de censura. (Art. $113 \mathrm{CE}$ ), ésta no llegó nunca a materializarse.

d) Control sobre disposiciones del Gobierno con fuerza de ley

Como ya hemos señalado anteriormente al tratar las prácticas aplicativas de la Constitución de carácter legislativo, el Gobierno presentó ante el Congreso de los Diputados para su convalidación o derogación 38 Derecretos-leyes. Todos ellos fueron convalidados.

e) Referéndum consultivo (véase lo dicho en esta crónica en el apartado relativo a prácticas aplicativas de la Constitución de carácter no legislativo).

\section{Actos de control sin eficacia jurídica}

a) Proposiciones No de Ley

De acuerdo con los datos provisionales facilitados por el Congreso de los Diputados, se presentaron ante la Mesa del Congreso 224 Proposiciones no de ley, de las cuales se tramitaron 193 y caducaron 31. Sólo 40 de ellas fueron aprobadas. Señalamos a continuación algunas de las más significtivas:

\begin{tabular}{clc} 
BOCG, $D$ & \multicolumn{1}{c}{ Materia } & $\begin{array}{c}\text { Grupo } \\
\text { Proponente }\end{array}$ \\
\hline 1 & $\begin{array}{l}\text { Necesidad de modifi- } \\
\text { car el régimen jurídico } \\
\text { de la letra de cambio. }\end{array}$ & M. CATALANA \\
32 & $\begin{array}{l}\text { Información periódica } \\
\text { del Gobierno sobre la } \\
\text { evolución de los ni- } \\
\text { veles de desempleo y } \\
\text { paro. }\end{array}$ & $\begin{array}{l}\text { M. CATALANA } \\
\text { y G. POPULAR }\end{array}$ \\
& $\begin{array}{l}\text { Política del Gobierno } \\
\text { en relación con la po- } \\
\text { lítica científica e inno- } \\
\text { vación tecnológica. }\end{array}$ & M. CATALANA
\end{tabular}




\begin{tabular}{clc} 
BOCG, A & \multicolumn{1}{c}{ Materia } & \multicolumn{1}{c}{$\begin{array}{c}\text { Grupo } \\
\text { Proponente }\end{array}$} \\
\hline 89 & $\begin{array}{l}\text { Política del Gobierno } \\
\text { en relacion con el } \\
\text { proceso de reconver- } \\
\text { sión industrial. }\end{array}$ & M. CATALANA \\
100 & $\begin{array}{l}\text { Administración de } \\
\text { Justicia en España. }\end{array}$ & M. CATALANA \\
145 & $\begin{array}{l}\text { Constitución de la } \\
\text { Comisión Parlamen- } \\
\text { taria de investigación } \\
\text { sobre la financiación } \\
\text { de los partidos polí- } \\
\text { ticos. }\end{array}$ & SOCIALISTA \\
183 & $\begin{array}{l}\text { Discriminación en el } \\
\text { lenguaje. }\end{array}$ & \\
\hline 191 & $\begin{array}{l}\text { Creación de un ór- } \\
\text { gano administrativo } \\
\text { de la Comunidad Gi- } \\
\text { tana y plan de desa- } \\
\text { rrollo. }\end{array}$ & \\
\hline & SOCIALISTA & \\
\hline
\end{tabular}

El Grupo Parlamentario que mayor número de Proposiciones no de Ley presentó fue el Grupo POPULAR con 94 (sólo 17 aprobadas), seguido del Grupo MIXTO con 54 (8 aprobadas), MINORIA CATALANA con 29 (8 aprobadas), SOCIALISTAS con siete (todas aprobadas) y los CENTRISTAS con cinco (ninguna aprobada) y el GRUPO VASCO con dos (ninguna aprobada).

\section{b) Interpelaciones}

\section{$\left.b_{1}\right)$ Interpelaciones ordinarias}

Al amparo de lo dispuesto en el artículo 181 y ss. del Reglamento de la Cámara, se presentaron 68 interpelaciones, pasando 65 de ellas a pregunta con respuesta escrita. Las tres restantes caducaron por disolución de la Cámara. El Grupo POPULAR fue el grupo parlamentario que en más ocasiones interpeló al Gobierno (46 interpelaciones), seguido de la Minoría CATALANA (8 interpelaciones), del Grupo MIXTO (10) y los CENTRISTAS (1 interpelación). 


\section{$b_{2}$ ) Interpelaciones urgentes}

De conformidad con lo dispuesto en la Resolución de la Presidencia para desarrollo de los artículos 181 a 184 del Reglamento del Congreso de los Diputados, en relación con el artículo 67,4 de dicho Reglamento, de 6 de septiembre de 1983, se presentaron 114 interpelaciones urgentes, de las cuales 64 fueron formuladas, ocho retiradas y 42 decaídas. Con 38 interpelaciones urgentes, el Grupo POPULAR se constituye en el primer grupo interpelante de la Cámara en la pasada Legislatura.

\section{c) Preguntas}

De las 1.130 preguntas presentadas para ser formuladas oralmente en el Pleno de la Cámara, sólo se formularon finalmente 841. Con respuesta oral en Comisión se tramitaron 217, y finalmente con respuesta por escrito se tramitaron 8.025.

\section{d) Comunicaciones del Gobierno}

De acuerdo con lo establecido en los artículos 196 y 197 del Reglamento de la Cámara, reguladores del procedimiento a través del cual se debe desarrollar el debate a que dé lugar una Comunicación del Gobierno remitida al Congreso, se debatieron siete Comunicaciones del Gobierno, de las cuales señalamos a continuación las más significativas:

BOCG, D

1,1

5,1

8,1
Debate sobre política exterior.

Materia

DSC n.

Resolución BOCG n. ${ }^{\circ}$

\begin{tabular}{|c|c|c|c|}
\hline 1,1 & $\begin{array}{l}\text { Debate sobre política ex- } \\
\text { terior. }\end{array}$ & 65,66 & $\mathrm{D}, 1, \mathrm{II}$ \\
\hline 5,1 & $\begin{array}{l}\text { Debate sobre política ge- } \\
\text { neral (estado de la Nación } \\
\text { 1984). }\end{array}$ & $157,158,159,160$ & $\mathrm{D}, 5, \mathrm{II}$ \\
\hline 8,1 & $\begin{array}{l}\text { Debate sobre el estado de } \\
\text { la Nación (1985). }\end{array}$ & 23̧7, 238, 239. & $\mathrm{D}, \mathbf{8}, \mathrm{II}$ \\
\hline & informativas de & $\stackrel{\circ}{\text { Pleno }}$ & \\
\hline
\end{tabular}


la Junta de Portavoces, deben comparecer ante el Pleno para informar sobre un asunto determinado. La iniciativa para la adopción de dichos acuerdos corresponde a dos Grupos parlamentarios o a la quinta parte de los miembros de la Cámara.

En la Legislatura 1982/1986, aunque hubo ocho solicitudes de acuerdo, el Gobierno sólo compareció ante el Pleno en una ocasión, a iniciativa propia, para informar, a través del Ministro del Interior, sobre las medidas en materia de lucha contra el terrorismo (DSC $n .{ }^{\circ} 69$ ). Las solicitudes mencionadas fueron rechazadas por la Mesa o retiradas en Junta de Portavoces.

\section{ACTIVIDADES DE INTEGRACION DE OTROS ORGANOS POLITICOS}

\section{Por imperativo constitucional}

a) Propuesta al Rey del nombramiento de Magistrados del Tribunal Constitucional

En cumplimiento de lo establecido en el artículo 159 de la Constitución, y en la Ley Orgánica del Tribunal Constitucional, el Congreso de los Diputados adoptó en 1983 y en 1986 los acuerdos de propuesta al Rey el nombramiento de los Magistrados del Tribunal Constitucional que le corresponden en la renovación de un tercio del alto Tribunal.

\section{b) Propuesta al Rey del nombramiento de miembros del Consejo General del Poder Judicial}

En cumplimiento de lo establecido en el artículo 122.3 de nuestra Constitución y en la Ley Orgánica del Poder Judicial, el Congreso de los Diputados designó a los miembros que le corresponden del Consejo General del Poder Judicial, y acordó en sesión plenaria remitir al Rey la propuesta de sus nombramientos (2 de octubre de 1985).

\section{Por imperativo legal}

a) Elección de los miembros del Consejo de Universidades

De acuerdo con lo dispuesto en la Ley Orgánica de Reforma Universitaria el Congreso de los Diputados eligió en su sesión plenaria de 15 
de febrero de 1984 a cinco de los miembros del Consejo de Universidades.

b) Elección de vocales del Consejo de Administración de RTVE

De conformidad con lo estipulado en el artículo 7.1 del Estatuto de RTVE, el Congreso de los Diputados eligió en sesión plenaria de 11 de mayo de 1983 a seis de los vocales del Consejo de Administración del Ente Público RTVE.

\section{c) Elección de miembros del Consejo de Seguridad Nuclear}

En cumplimiento de lo dispuesto en la Disposición Transitoria $1 .^{\mathrm{a}} \mathrm{y}$ en el artículo 5,2 de la Ley 15/1980 de 22 de abril de creación del Consejo de Seguridad Nuclear, la Comisión de Industria, Obras Públicas y Servicios del Consejo de los Diputados aprobó por mayoría de 3/5 la propuesta de nombramiento de miembros de dicho Consejo.

\section{RELACIONES CONGRESO-TRIBUNAL CONSTITUCIONAL}

De los 296 procedimientos del Tribunal Constitucional relacionados con el Congreso, éste sólo se personó en tres conflictos constitucionales planteados por el Consejo General del Poder Judicial en relación al Proyecto de ley orgánica del Poder Judicial (Conflictos 495/85; 788/85 y 797/85), y en un recurso de amparo promovido por dos diputados contra la declaración del Congreso que priva derechos y prerrogativas de los diputados (164/83).

\section{ACTIVIDADES DEL CONGRESO RELACIONADAS CON LAS COMUNIDADES AUTONOMAS}

\section{Actividad de carácter normativo}

En la Legislatura pasada se completó prácticamente el llamado mapa autonómico con la aprobación de los Estatutos de Autonomía de Baleares, (DSC n. 7,9 y 13), Extremadura (DSC n. ${ }^{\circ} 8$ ), Castilla-León (DSC n. ${ }^{\circ}$ y 13) y Madrid (DSC $n .^{\circ} 8$ ), quedando tan sólo pendientes los 
de Ceuta y Melilla, proyectos de ley que caducaron a consecuencia de la disolución de la Cámara.

Asimismo se produjo mediante ley la cesión de los tributos del Estado a las Comunidades Autónomas de Cantabria, Murcia, Aragón, Asturias, Andalucía, Galicia, Castilla-La Mancha, Castilla-León, La Rioja, Canarias, Valencia, Extremadura y Madrid (BOCG, A, 36 a 44, 62, 63, 64, 69 y 72).

Asimismo se fijó por ley los porcentajes de la participación de las Comunidades Autónomas en los ingresos del Estado.

PILAR MELLADO PRADO

Nota: Mi agradecimiento a DON MANUEL GONZALO, Letrado de las Cortes Generales, por la documentación facilitada para la elaboración de esta Crónica. 